\title{
From "Her" Problem to "Our" Problem: Using an Individual Lens Versus a Social-Structural Lens to Understand Gender Inequity in STEM
}

\author{
Kathi N. Miner, Jessica M. Walker, Mindy E. Bergman, Vanessa A. Jean, \\ Adrienne Carter-Sowell, Samantha C. January, and Christine Kaunas \\ Texas A\&M University
}

\begin{abstract}
Increasing the representation of women in science, technology, engineering, and mathematics (STEM) is one of our nation's most pressing imperatives. As such, there has been increased lay and scholarly attention given to understanding the causes of women's underrepresentation in such fields. These explanations tend to fall into two main groupings: individual-level (i.e., her) explanations and social-structural (i.e., our) explanations. These two perspectives offer different lenses for illuminating the causes of gender inequity in STEM and point to different mechanisms by which to gain gender parity in STEM fields. In this article, we describe these two lenses and provide three examples of how each lens may differentially explain gender inequity in STEM. We argue that the social-structural lens provides a clearer picture of the causes of gender inequity in STEM, including how gaining gender equity in STEM may best be achieved. We then make a call to industrial/organizational psychologists to take a lead in addressing the societal-level causes of gender inequality in STEM.
\end{abstract}

Keywords: STEM, women, gender equity, workplace, I-O psychology

There has been a tremendous increase in women's labor force participation in the last 50 years (Juhn \& Potter, 2006; Mosisa \& Hipple, 2006), particularly in the fields of education, health services, retail, and secretarial and administrative assistants (Department of Labor, 2014). However, the number of women in science, technology, engineering, and mathematics (i.e., STEM fields) remains dismally low. In the U.S., women fill close to half of all jobs in the economy but hold fewer than 30\% of STEM jobs (National Science Foundation [NSF], 2015). Additionally, women earn $41 \%$ of PhDs in STEM fields but only make up $28 \%$ of tenure-track academic faculty, and they are

Kathi N. Miner, Texas A\&M University; Jessica M. Walker, Texas A\&M University; Mindy E. Bergman, Texas A\&M University; Vanessa A. Jean, Texas A\&M University; Adrienne Carter-Sowell, Texas A\&M University; Samantha C. January, Texas A\&M University; Christine Kaunas, Texas A\&M University.

Correspondence concerning this article should be addressed to Kathi N. Miner, Department of Psychology, TAMU 4235, Texas A\&M University, College Station, TX 77843. E-mail: kminer@tamu.edu 
particularly scarce at the full professor level in these fields (NSF, 2015). Even in psychology, where women started earning more than half of the doctoral degrees as of 1986, women constitute less than half of the full professors (41\%). The numbers for women of color are even bleaker in that they comprise fewer than 1 in 10 employed scientists and engineers (NSF, 2015).

The underrepresentation of women in STEM is a social issue affecting America's global competitiveness and the American people. The U.S. will face an estimated deficit of one million workers for STEM jobs over the next decade (President's Council of Advisors on Science and Technology [PCAST], 2012); one solution to this problem is to encourage the "underrepresented majority" (e.g., women, underrepresented ethnic minority persons) to enter STEM fields (PCAST, 2012). Moreover, the inclusion of women in STEM positively predicts the quality and reach of STEM research (Freeman \& Huang, 2014). Thus, the current lack of women in STEM limits innovation and research discoveries. Advancing the engagement of women in STEM is not only an essential part of America's strategy to remain globally competitive; it is also vital to the social status of individual women. Women in STEM jobs earn 33\% more than those in non-STEM occupations and, as a result, experience a smaller wage gap relative to men (NSF, 2015). As such, the entry and retaining of women in STEM is an essential step toward realizing greater economic equality for American women.

The awareness of the need for more women in STEM has led to a focus on the causes of women's underrepresentation in these fields, even at our nation's highest levels. For example, The U.S. Office of Science and Technology Policy (whitehouse.gov/administration/eop/ostp/women), in collaboration with the White House Council on Women and Girls (whitehouse. gov/administration/eop/cwg), is dedicated to increasing the participation of women and girls in STEM by engaging girls with STEM subjects, encouraging mentoring initiatives to support women in STEM, and supporting efforts to retain women in the STEM workforce. There is also a plethora of national organizations whose mission is to encourage girls and women to pursue and remain in STEM careers including the National Girls Collaborative Project (ngcproject.org), Girls Who Code (girlswhocode.com), Change the Equation (changetheequation.org), American Association of University Women (aauw.org), Million Women Mentors (millionwomenmentors.org), and Association of Women in Science (awis.org). The NSF is also addressing this issue through its ADVANCE program (www.nsf.gov/funding/pgm_summ. jsp?pims_id=5383), which aims to develop systemic approaches to increase the representation and advancement of women in academic STEM careers, develop innovative and sustainable ways to promote gender equity in the STEM academic workforce, and contribute to the development of a more diverse STEM workforce. 
The general public has also focused attention on the factors that deter women from entering and remaining in STEM fields, often sparking national conversations and debate. For example, a recent search on Google.com for news stories related to "women in STEM fields" resulted in 45,800 hits and included headlines such as "Nobel scientist Tim Hunt: female scientists cause trouble for men in labs... [they] 'fall in love with you and when you criticise them, they cry" (Ratcliffe, 2015); "Choices - not discrimination determine women scientists' success, researchers say" (Ju, 2011); "Stereotypes lower math performance in women, but effects go unrecognized" (IU Bloomington Newsroom, 2015); and "Gender and racial bias is systemic in the sciences" (Phillips, 2015).

These explanations-“typical" female behavior, women's career and family choices, stereotypes about women, bias, and sexism-point to the multitude of explanations for understanding gender inequity in STEM. They also suggest very different lenses by which to understand gender disparity in STEM: those that originate from women themselves and those that originate from societal ideas about women. The purpose of the present article is to describe these two lenses and how they lead to different explanations for gender inequity in STEM. Further, we describe how using an individuallevel lens provides a problematic assessment of gender inequity in STEM and how a social-structural lens results in a more accurate explanation of why gender disparity in STEM occurs and how it can be remedied. We conclude by making the case that industrial and organizational (I-O) psychologists have a responsibility, as scholars and practitioners of the workplace, to help lead the effort in addressing and rectifying the social-structural causes of women's inequity in male-dominated fields like STEM.

\section{Two Lenses for Understanding Gender Inequity in STEM The Individual Lens}

Taking an individual lens means focusing on individual choices, actions, histories, attitudes, or beliefs as causes of group differences. In the case of gender inequity in STEM, the individual lens focuses on self-selection and fit as the proximal cause of the STEM gender gap, such that women are less likely to select and are less suited to STEM careers than are men. This perspective is often backstopped by claims such as "women are less interested in STEM careers" (McArdle, 2008; Rosenbloom, Ash, Dupont, \& Coder, 2008) or "men have greater aptitude for STEM careers" (e.g., Larry Summers's 2015 Harvard address) to explain the gender gap in STEM workforce participation. Although these claims do not necessarily explicitly rule out the possibility of social-structural causes for these differences (e.g., it could be the case that interest differences across sex are caused by social structures that push men toward STEM careers and women away from them), addressing the issue of 
the social-structural causes underlying self-selection or fit is unusual or an afterthought. The framing of the statements at the individual level reifies the role of individuals as the agents of gender inequity.

Additionally, there are often essentialist implications of claims made via the individual lens, although these essentialist implications are often unstated and therefore neither examined nor rejected. For example, when there is a claim like "men have greater aptitude for STEM careers," the implication is that aptitude is inborn and inherently different between men and women; however, it is possible that such differences are caused via early schooling differences, parental choices in encouraging child interests and hobbies, and other early reinforcement differences that are societally based. Despite the problems associated with the individual lens, it remains a popular and common perspective for understanding why gender inequity in STEM exists. Why might this be the case?

There are numerous psychological reasons ${ }^{1}$ why the individual lens is used, but they generally boil down to two reasons: ease and values. First, the individual lens is easy to use because of limitations of human cognitive processing. For example, a central tenet of attribution processes is correspondence bias-a tendency for people to use individual actor explanations for individual actor behavior unless there is motivation to seek out alternative explanations or when faced with surprising or unexpected information (Gilbert \& Malone, 1995). As such, most human judgments are automated and heuristically driven because automatic judgments are easy to reach and seem correct on their surfaces (Kahneman, 2011; Tversky \& Kahneman, 1974). Further, people are aware of their own selves, see themselves as actors and objects, and focus on their selves as explanations for their own experiences (McAdams \& Pals, 2006; Silvia \& Duval, 2001). In addition, people are usually motivated to look for evidence to confirm their beliefs rather than evidence that is disconfirming (Nickerson, 1998). For instance, someone who holds the belief that anyone can succeed if they put in enough effort can easily identify highly successful women (e.g., women CEOs, women provosts) as evidence of their stance. Such evidence suggests that all women could succeed if they "just worked harder." This perspective therefore suggests that gender inequity can be overcome by the actions of individual women. People forget that these women, although exceptional, are also exceptions (Valian, 1999). Further, individuals lack the ability to fully understand structural causes of disadvantage. Structural explanations are much more complicated than individual explanations, involving greater numbers

1 We acknowledge that these explanations might be particularly Western, as there are clear differences in construal of the self, figure-ground cognitive properties, and attributions across cultures (Henrich, Heine, \& Norenzayan, 2010; Markus \& Kitayama, 1991). 
of factors and requiring the gathering of more evidence (e.g., demonstrating that disadvantage happens to many people from one group and fewer people from other groups). People are particularly inept at dealing with complex problems and tend to prefer simple, "good enough" explanations relative to those that are more complex (Gigerenzer \& Selten, 2002; Kahneman, 2003, 2011; March \& Simon, 1958; Simon, 1991).

The second general reason that people rely on the individual lens is because it reinforces the individualist values of Western culture (Henrich, Heine, \& Norenzayan, 2010; Hofstede, 2001; House, Hanges, Javidan, Dorfman, \& Gupta, 2004). Individualism is the cultural value that individual interests, individual attitudes, rational motives, and personal goals are promoted over communal interests, group norms, relational motives, and group goals (i.e., collectivism; Triandis, 1995). For example, the Protestant work ethic (PWE) refers to the belief in the importance of individual hard work and frugality, and that a strong work ethic is the main determinant of individual prosperity (Morrow, 1993; Weber, 1958). As such, individuals who are not prospering are simply not trying hard enough (van Hoorn \& Maseland, 2013; Weber, 1958). PWE justifies negative outcomes across groups as being due to a lack of effort rather than structural disadvantages that put one group in a position of being unable to compete or succeed (Biernat, Vescio, \& Theno, 1996; Christopher \& Mull, 2006; Furnham, 1982; Heaven, 1990; Schmader, Johns, \& Barquissau, 2004; Swim, Aikin, Hall, \& Hunter, 1995).

Individualism at the cultural level therefore promotes a focus on individual explanations for behavior and outcomes. That is, the individual lens is a product of the larger culture, in that how people interpret individual behavior is influenced by the values and norms of the larger societal context. Together, these factors encourage us to look at the individual level to explain lack of advancement of women in STEM rather than structural causes to explain women's disadvantage. They also lead people (including women and men themselves regarding their own decisions) to assume that women's and men's choices and behaviors are freely and actively made without considering larger social-contextual influences.

As psychologists, the individual lens is familiar. We generally focus on individuals and their knowledge, skills, and abilities, their job attitudes, and their workplace experiences. Although we also focus on multiperson processes and constructs (e.g., supervisor-subordinate dyads, teamwork, organizational climate), they are often still defined as collective versions of individual phenomena rather than social-structural phenomena. As an example, the common way of assessing organizational climate at the group level is to assess individual perceptions of climate and then aggregate them to the group level. This operationalization is appropriate given the construct definition in our field, but it does not account for the ongoing, interpersonal 
nature of climate nor relevant social-structural factors. Our point is that the focus of I-O psychology—and most psychology—on individual factors is not wrong but rather incomplete; in some cases, the focus on individual factors can be misleading of the underlying causes of organizational phenomena. We turn next to the definition and discussion of the social-structural lens as a contrast to the individual lens.

\section{The Social-Structural Lens}

An alternative to using an individual lens for understanding gender inequity in STEM is to use a social-structural lens. Using a social-structural lens entails taking a broader perspective for explicating the causes of gender inequality by linking the differential experiences of women and men to larger societal structures, processes, and meanings associated with gender rather than individual behavior, choices, and preferences void of context. Because this lens encompasses the role society plays in gender inequity, it suggests that everyone-both women and men-contribute to the perpetuation of gender roles and expectations and, subsequently, oppression.

Acknowledging the ways in which people personally contribute to gender inequality can be cognitively threatening and, as such, can be psychologically difficult. Research shows that people have a strong need to feel good about themselves (Crocker \& Wolfe, 2001; Leary \& Baumeister, 2000; Sedikides \& Strube, 1997). If people can blame someone for their disadvantages, they are "off the hook" and can continue to see themselves as good and fair people (Jost, Banaji, \& Nosek, 2004; Kluegel \& Smith, 1986; Lerner, 1980). However, there is substantial evidence that the meanings associated with gender in the larger society-which everyone helps create-impact both women's and men's work lives, including in STEM. Moreover, society develops, or constructs, meanings associated specifically with gender and work. In this section, we describe the social construction of gender and work, and how it may inform our understanding of gender inequity in STEM.

Several theories illuminate the social-structural lens. Some of these are familiar to psychologists (e.g., social exchange theory, social dominance theory), although here we include societal factors that provide additional context to how these theories play out in real life experiences. Others of these might be less familiar to psychologists, as they draw on sociology, women's and gender studies, and other fields. This review is not meant to be exhaustive but rather an overview of key ideas in the social-structural perspective. We begin with social constructionism, as it is the bedrock of our understanding and critique of individual and essentialist focuses on gender inequity.

Social constructionism. Social constructionism (Berger \& Luckmann, 1966) is a sociological theory of knowledge proposing that people develop their understandings of the world through social order. Berger and 
Luckmann (1966) argued that individuals understand the world in conjunction with others via socially imposed constraints and predefined notions of acceptable behavior. They maintained that

social order is not part of the "nature of things," and it cannot be derived from the "laws of nature." Social order exists only as a product of human activity.... Both in its genesis (social order is the result of past human activity) and its existence in any instant of time (social order exists only and insofar as human activity continues to produce it). (Berger \& Luckmann, 1966, pp. 51-55, 59-61)

They further proposed that social institutions (e.g., work, family, education) play a critical role in this process by defining appropriate behavior specific to those contexts. Over time, these predefined and consistent constraints lead to perceiving behavior as objective (or "natural") and selfinitiated rather than compelled by society and malleable.

Our understanding of the relationship between gender and work can be described as socially constructed in that it is developed and maintained though social interaction and is constrained by social institutions. For example, because women have traditionally worked inside the home and men outside the home, people assume that women are naturally better at taking care of home and family, and men are inherently superior in the world of paid labor. These meanings then act as a form of social control by defining acceptable behavior for women and men regarding work (Lorber, 1994; Ridgeway, 1997; Ridgeway \& Correll, 2004). Such definitions may then lead to disparate behavior and choices, which are assumed to be the result of differences in individual-level characteristics, such as choices or aptitude, rather than the influence of society (Ceci, Williams, \& Barnett, 2009; Harton \& Lyons, 2003; Smith-Lovin \& McPherson, 1993). In other words, gendered employment patterns reproduce themselves, and this reproduction appears to be both natural and individually chosen, as it is how "it has always been done," when in fact it is-and continues to be-socially constructed.

Gendered work practices (Martin, 2003, 2006) are those aspects of the work world (e.g., who does what type of work, how work tasks are best accomplished) that are assumed to result from gender-based, individual-level choices rather than societal-level constraints (Ridgeway \& Correll, 2004). Gendered work practices are especially relevant to understanding women's experiences in male-dominated fields like STEM because the foundation and culture of these fields is framed around the social construction of masculinity and the association between men and the public sphere of work. For example, academic science imposes a set of norms and expectations dictating that scientists are decisive, methodical, objective, unemotional, and competitivecharacteristics associated with men and masculinity (Acker, 1990; Martin, 2001, 2003; Miller, 2004). Indeed, the prototypical scientist is perceived as having characteristics more congruent with the male gender role than the 
female gender role (Cheryan, Plaut, Davies, \& Steele, 2009; Diekman, Brown, Johnston, \& Clark, 2010; Margolis \& Fisher, 2002; Nosek, et al., 2009; Schott \& Selwyn, 2000). Disciplinary norms also expect scientists to adopt a work style that exhibits complete dedication to their work at the expense of any other obligations such as family or children (Acker, 1990). STEM physical environments can even send the message that women are unwelcome. For example, Cheryan et al. (2009) found that the more women perceived an environment (i.e., a computer science classroom) as masculine (e.g., by the display of Star Trek posters), the less they reported being interested in the field regardless of whether men or women numerically dominated the context. Interestingly, STEM disciplines, in particular, also seem to deny the presence of gendered practices and gender bias by promoting the notion that skill and merit solely determine success (Bagilhole \& Goode, 2001; Cech \& Blair-Loy, 2010; Krefting 2003).

Social exchange theory and social dominance theory. Social exchange theory also provides a framework for understanding how workplace gender inequity may occur. The core of social exchange relationships is reciprocation (Rousseau \& McLean Parks, 1993); social resources (e.g., social integration, information) provided by a source individual or organization encourage reciprocation by the target receiver (Cropanzano \& Mitchell, 2005; Emerson, 1976). Within this framework is the rule of status consistency: Resources are distributed to others based on their status and social standing in the group. Status beliefs derive from cultural processes that stereotype one group (e.g., men) as being superior to or more competent than another (e.g., women; Ridgeway, 1991, 1997). Because the status consistency rule of social exchange theory proposes that social resources are allocated based on status, individuals who are lower in social status due to cultural stereotypes could be seen as less valuable exchange partners and therefore experience less social exchange. Indeed, individuals belonging to stigmatized groups experience social exchange as a result of their collective group identity rather than their actual workplace behaviors; that is, individuals in low-status social groups may be excluded, or perceived as incompetent or as less well-suited to certain careers because of their social position, not because of their personal characteristics and accomplishments (O'Reilly \& Robinson, 2009; Settles \& O'Connor, 2014).

Social dominance theory (Sidanius \& Pratto, 1999) proposes that social groups are structured as systems of group-based hierarchies with dominant and subordinate groups. Group-based hierarchies refer to the social power, prestige, and privilege that individuals receive because of their memberships in particular social groups, such as gender. Individuals with dominant group membership (i.e., men) hold a disproportionately large share of "positive social value," such as power, social status, and material goods. In contrast, 
individuals with subordinate group membership (i.e., women) hold a disproportionately large share of "negative social value" such as low power, low social status, and minimal material goods. Together, social exchange (Rousseau \& McLean Parks, 1993) and social dominance (Sidanius \& Pratto, 1999) theories suggest that women in STEM may therefore receive fewer social resources from the start because of gender bias in the larger society.

Summary. Social constructionism, and the social construction of gender and work, propose that there are influences on women's and men's behavior that originate from larger societal structures that lead to gender inequality in the world of work. Nonetheless, people continue to rely on individuallevel explanations for understanding gender inequity in the workplace. Even when we psychologists study social exchange and social dominance theories, we often examine individual or dyadic level phenomena without considering the larger social-structural context. As we noted above, this is not a wrong perspective but an incomplete one. With our incomplete view on these phenomena, we as psychologists might accidentally be perpetuating the myths of individual choice in gendered employment patterns. To demonstrate this problem, we describe three common explanations for gender inequity in STEM that are constructed at the individual level, explain why the individual lens is problematic, and offer social-structural explanatory alternatives.

\section{Three Individual-Level Legitimizing Myths Associated With Gender Inequity in STEM}

In this section, we describe three prominent, yet problematic, individuallevel explanations for gender inequity in male-dominated workforces such as STEM. We then reframe each explanation using the social-structural lens. We propose that using an individual lens creates myths about women and work that legitimize gender inequity and that using a social-structural lens provides a more accurate account of gender inequity STEM.

\section{Legitimizing Myth \#1: There is gender inequity in STEM because women are not masculine enough to succeed in male-dominated workplaces.}

One prominent explanation for gender inequity in male-dominated work contexts such as STEM proposes that women are simply not masculine enough, and therefore unfit, to be successful in male-dominated fields like STEM. The general argument goes something like this:

Women, simply because they are women, have traits associated with femininity (such as empathy, emotionality, cooperation, and passivity) that are often unnecessary-and even unwanted-in the cut-throat world of maledominated work. Model workers in male-dominated fields like STEM are those who are competitive, rational, independent, and decisive-aspects inherent in masculinity. Moreover, women are simply interested in different topics than 
men and their interests are inherent to their femaleness. For example, women are interested in people and men are interested in objects. Because women do not have these masculine characteristics to the extent that men do, they will never achieve equity with men unless they "man up" and behave in a more masculine manner.

When framed this way, the responsibility for gender inequity in maledominated fields like STEM is put on women and their lack of masculine traits and interests. Heilman $(1983,2001)$ described this as the "lack of fit" model. This model states that expectations of a person's job performance are based on perceived fit between the individual's attributes and the job's requirements. If the perceived fit is good, expectations for success will be high; if the perceived fit is poor, expectations for success will be low. Thus, the more masculine in sex type the job, the worse the perceived fit and the more negative the expectations for women's success (Heilman, 1983, 2001). In short, people view women as unfit for certain jobs and occupations (e.g., scientist, engineer) because they see women as not holding the attributes needed for the role (Eagly \& Karau, 2002). For STEM, this means that the perceived lack of fit between STEM occupations and women is therefore likely to produce expectations of failure.

The notion that women are inherently unfit for masculine jobs is problematic because it places blame on individual women while neglecting the role society plays in constructing and perpetuating stereotypes associated with women and men and about the inherent nature of jobs and workplaces. Stereotypes are beliefs about the characteristics and behavior of individuals of certain demographic groups (Hilton \& von Hippel, 1996). For example, women are believed to be compassionate, kind, cooperative, and emotional. Men, in contrast, are believed to be assertive, competitive, ambitious, and independent. These attributes for women and men are described as communal (or social and service-oriented traits) and agentic (or achievement-oriented traits) respectively (Bakan, 1966). Stereotypes of women and men are not only different, but they are also oppositional in that members of one sex are seen as deficient in, and prohibited to have, the traits that are presumed to be the most prevalent in the other sex (Heilman, 2001).

There is ample evidence to support Heilman's $(1983,2001)$ lack of fit model and its application to perceptions of women, men, and their ability to perform in certain jobs. For example, Lyness and Heilman (2006) reported that women were rated less favorably than men in traditionally male jobs (line jobs) but not in traditionally female jobs (staff jobs), even after controlling for a host of human capital variables (e.g., organizational tenure, education). Similarly, Pazy and Oron (2001) found that unless there was gender parity within the unit, women's competence and performance were rated significantly lower than men's in military units. Gormann (2005) found that 
when selection criteria in law firms included a greater number of stereotypically masculine characteristics (e.g., independence), fewer women lawyers were hired compared to when selection criteria included more stereotypically feminine traits (e.g., friendliness); these findings occurred in the absence of objective measures of applicants' levels of these attributes. Findings from a content analysis of letters of recommendation for faculty at a U.S. medical school demonstrated that letters written on behalf of men were longer and focused on their achievements and research productivity whereas letters written on behalf of women were shorter, focused more on teaching, and included more "doubt raisers" such as faint praise and hedges (Trix \& Penska, 2003). Several experiments using identical curriculum vitaes that only differed by the obviously gendered name of the applicants (e.g., John vs. Jane) resulted in male applicants receiving higher scores, being preferred more, and receiving higher starting salaries than women; this effect was found whether the rater was a man or a woman (Moss-Racusin, Dovidio, Brescoll, Graham, \& Handelsman, 2012; Steinpreis, Anders, \& Ritzke, 1999). ${ }^{2}$ In another study, women had to be nearly 2.5 times more productive than men in order to receive the same ratings of competence from judges for a biomedical postdoctoral fellowship in Sweden (Wennerås \& Wold, 1997).

One of the most compelling studies regarding the effect of stereotypes on the selection of women into male-dominated fields examined the change in orchestras' demographic compositions with the advent of the blind audition (Goldin \& Rouse, 2000). A blind audition occurs when musicians audition behind a screen (and often with other gender-obfuscating tactics, such as removal of shoes or several people walking to the audition chair together), leaving only the performance itself to be judged by the selection panel. Goldin and Rouse (2000) examined orchestra audition records and rosters before and after the implementation of blind auditions at 11 U.S. major city orchestras. Prior to the incorporation of blind auditions, orchestras were predominantly male; women comprised $10 \%$ or fewer new hires or roster members of most major orchestras. Switching to blind auditions increased the probability that women would advance from early audition rounds by $50 \%$ and accounted for nearly one-third of the increase in the proportion of women among new hires. These findings provide evidence that gender stereotypes are a better explanation for gender inequity in

2 This effect has also been found for race (resumes with either "black-sounding" or "whitesounding" names based on social security data for names that are popular within only Caucasian or African-American families); having a "white sounding" name was equivalent to 8 additional years of experience (Bertrand \& Mullainathan, 2004). Research also shows that ostensibly having a disability translates into negative outcomes (e.g., less likelihood of receiving a job offer) for potential employees (Ren, Paetzold, \& Colella, 2008). 
male-dominated work contexts like STEM than are women's individual characteristics and traits.

Practical recommendations for I-O psychologists. I-O psychologists can use this information to redesign selection systems in order to reduce bias. Indeed, many of I-O psychology's common procedures are already helpful in reducing bias; for example, job analysis and competency modeling, selection tests, and structured interviews all contribute to a standardized understanding of the job's requirements and the applicants' abilities. However, I-O psychologists should not assume that utilizing systematic processes equates to eradicating bias. I-O psychologists should take the extra step to critically examine the gendered content of job descriptions and selection modules. One tool that could be useful in scrutinizing these is the gender-bias calculator (http://www.tomforth.co.uk/genderbias/). Although this tool is designed for letters of recommendation, it can be used for any text. Additionally, I-O psychologists can keep a dictionary of gendered descriptors or terms and more neutral alternatives (e.g., kind could be restated as respectful). Relatedly, I-O psychologists should be sure to do more than accept a word as a descriptor (e.g., "assertive") and instead drill down to make sure that the underlying ideas are represented.

I-O psychologists are also skilled at examining the relationship between selection models and job performance. However, it is important to recognize that gender norms influence both selection models and assessments of job performance. That is, implicit biases do not only unduly influence our understanding of who is suited to a job but also (a) how good performance is defined and (b) whether an individual's performance meets those criteria. A prime example of this comes from the policing literature. Police jobs are highly masculine (Bureau of Labor Statistics, 2016; Spillar et al., 2000). Yet evidence shows that women (a) police in ways that are different from men's policing behavior (Bergman, Walker, \& Jean, 2016; Lonsway et al., 2002; Schuck \& Rabe-Hemp, 2007) and (b) are just as effective-if not more effective-at policing (Bergman et al., 2016; Lonsway et al., 2002; Spillar, 2015). Making sure that such evidence is accounted for when developing selection and appraisal systems is paramount to improving gender parity in male-dominated fields.

\section{Legitimizing Myth \#2: There is gender inequity in STEM because women choose not to have STEM careers.}

Another misconception regarding gender inequity in STEM is that women actively and independently choose not to have STEM-related careers (e.g., to focus on family) or choose jobs (e.g., research assistants, nontenure-track positions) that put them in unequal positions compared to men. The argument typically proceeds like this: 
Everyone has free will to make their own choices. Women certainly can pursue prestigious STEM careers if they desire, but they choose not to or they take less demanding positions. Women often make these choices because they see STEM occupations at odds with raising a family, childcare, or other personal and family needs. When women make the choice to focus on family over career, they need to accept the consequences of that choice, even if it results in gender inequity (e.g., lower pay, lower status). Hence, women are liable for gender inequity in STEM because of their individual choices. To receive equity with men in STEM, women should choose their career over other life choices.

When framed this way, the gender inequity problem is placed on women and their "autonomous" life decisions. In essence, the notion is that women have the capability to gain gender equity in male-dominated fields like STEM simply by choosing to put their careers above other pursuits. This explanation is problematic because it ignores important differences between men and women (e.g., pregnancy, birth, and lactation, gender roles surrounding parenting) and how the notion of choice is constructed in society.

Certainly, choice is not a bad thing; having choices can lead to a number of positive consequences for individuals including increased motivation, better physical health, and heightened psychological well-being (Patall, Cooper, \& Robinson, 2008). Choice also allows people to experience themselves as responsible for their own lives. Markus and Kitayama (2003) call this psychological stance the disjoint model of agency and maintain that the notion of individual choice is linked with beliefs about independence, control, and freedom from societal constraints. However, beliefs about individual choice can also lead to negative consequences, particularly for those living in individualistic cultures. Because of the disjoint model of agency (Markus \& Kitayama, 2003), when the concept of choice is activated, people perceive individuals as responsible for their own actions and life outcomes, regardless of social circumstances. Savani, Stephens, and Markus (2011) found that simply activating the concept of choice led Americans to perceive disadvantaged individuals as responsible for their situation (i.e., to blame the victim), feel less empathy for them, and be less likely to support policies to promote social equality. Savani and Rattan (2012) examined whether the concept of choice leads Americans to act in ways that perpetuate wealth inequality. They found that thinking in terms of choice activated the belief that life outcomes stem from personal agency, not societal factors, thereby justifying economic disparities. Stephens and Levine (2011) proposed that the cultural assumption that actions originate from individual choices conceals workplace barriers against women by suggesting individual behavior is separate from context.

Kricheli-Katz $(2012,2013)$ examined how what she calls choice-based discrimination affects women and minorities in the workplace. She defines 
this form of discrimination as one in which an individual is treated more negatively when the stigmatized characteristics they hold are believed to be controllable. She posits that moral judgments associated with perceptions of an attribute as voluntary legitimize the expression of biases and stereotypes against the person who holds the attribute, which then generates discrimination. For example, Kricheli-Katz (2012) proposed that the degree to which motherhood is conceptualized as a choice affects the extent to which women are discriminated in the labor market. Using Current Population Survey data from 1988-2004, she found that after accounting for individual and state-level factors that affect wages, mothers received significantly lower wages in states where motherhood was perceived to be a woman's choice (measured, for example, by the percent of nonmothers 16-40 years). In a second study using an experimental paradigm, she found evidence for a relationship between perceptions of choice and hiring discrimination against mothers. She maintained that employers may see the negative differential treatment of mothers as morally justifiable when motherhood is seen as under women's personal control. In another study, Kricheli-Katz (2013) found that gay men, obese men, and mothers were discriminated against more in terms of hiring, salary recommendations, and competence evaluations when the traits they held were perceived to be related to their personal choices. Similarly, Stephens and Levine (2011) found that simply exposing research participants to a message that frames women's actions in terms of individual choice (i.e., mothers opting out of the workforce) increases participants' beliefs that society provides equal opportunities for women and men and that gender discrimination no longer exists. This research suggests that people perceive gender inequity as warranted when women make the decision to mother and that women are therefore responsible for that inequity.

Investigating other reasons behind women's career choices, Frome, Alfeld, Eccles, and Barber (2006) examined potential reasons why young women alter their career plans from male-dominated occupations to femaledominated occupations. They posited that one reason may be society's expectation for women to be the primary caretaker of family and children and that this expectation may serve to funnel women into fields perceived to allow more flexibility (e.g., elementary education). They found that $83 \%$ of the women in their study who had male-dominated occupational aspirations in the 12th grade switched to female-dominated or neutral occupational aspirations by the time they were 25 years old. They also found that a desire for a family-flexible job and aspirations for a job without high time demands were some of the best predictors of women changing to a female-dominated job. Frome et al.'s (2006) findings suggest women's choices regarding their occupational aspirations are heavily influenced by the larger society and expectations regarding the social roles of men and women. 
More explicitly germane to women in STEM, Correll (2001) argued that social-structural beliefs about gender and math competence constrain the early educational and career choices of women and men by biasing their perceptions of competence at various skills. She maintained that when competence at a particular skill is linked to a specific career and gender differences in that skill are presumed to exist, individuals make educational and career decisions consistent with that belief regardless of their actual ability. Correll (2001) found that women perceived themselves to be less competent at math compared to men (even though grades and test scores revealed they were not), and that these perceptions influenced their decisions about pursuing a STEM career. She noted: "Boys do not pursue mathematical activities at a higher rate than girls do because they are better at mathematics ... they do so ... because they think they are better" (p. 1724; emphasis added). More recent research by Bench, Lench, Liew, Miner, and Flores (2015) also suggests that men pursue STEM careers more frequently than women because they believe they will be successful, not because women believe they will be unsuccessful.

These findings suggest that what may appear as individuals making independent and voluntary career choices may actually be individuals making decisions within a social-structural framework that biases their selfperceptions and others' perceptions of their competence and, in turn, their career aspirations. People assume women do not choose STEM fields because they dislike them, are not good at them, see them as too time consuming, or for some other reason. People may neglect to consider the socializers and barriers women encounter that turn them away from STEM fields. In short, the notion that women "choose" certain career paths must be understood within the larger social context in which those decisions are made.

Practical recommendations for I-O psychologists. I-O psychologists are generally concerned with the world of work, so some of the solutions to this problem fall outside the typical I-O psychology purview. For example, increasing interest in STEM career paths among all people-but especially women and underrepresented minorities-should occur in K-12 educational settings as well as colleges and universities. Additionally, the climate for women in STEM training programs needs to be more positive. Although educational settings are not common practice spaces for I-O psychologists, some I-O psychologists engage in this work and others partner with corporate outreach efforts; academic I-O psychologists are often called upon to consult with university departments about climate, retention, and recruitment. Thus, we encourage I-O psychologists to contribute to early education, STEM training programs, and attraction to STEM careers when they are able to and bring to bear the knowledge we have about implicit biases, climate, and choice. 
Legitimizing Myth \#3: There is gender inequity in STEM because women are not "ideal" workers.

A third misconception about the gender inequity in STEM fields is that women do not make ideal workers. The argument typically goes like this:

Women do not have the amount of time that men do to devote to their work. The ideal worker is fully committed to his job and is available to work or move when needed. Women cannot meet this expectation because they have to care for their families and perform familial duties. Additionally, a woman cannot stay or move as the job demands because her spouse or partner's job requirements and demands often take precedence. Because women cannot put their jobs above everything else, they will never be ideal workers and thus, are not suitable for male-dominated occupations like STEM, which require complete devotion. If gender equity is to be achieved, women must be able to fully commit to their work without any distractions, such as children. If they cannot, they are responsible for their own gender inequity.

Although there have been significant changes in the last few decades in the structure of work and how people work (e.g., compressed work weeks, flextime, remote-based work), most workplaces continue to revolve around traditional notions of work and what scholars call the ideal worker norm. The ideal worker norm refers to the social construction of the ideal worker. The ideal worker is someone who is entirely committed to his or her job and puts a job above all else; he or she is always available to work fulltime and overtime, will move or travel if and when necessary for the job, and have someone at home (e.g., a "wife") who is responsible for domestic matters and childcare (Williams, 2000). The ideal worker norm has permeated the world of work such that the best employees are thought to have the characteristics associated with the ideal worker norm. Because of this, women, especially women in male-dominated fields like STEM, are rarely considered ideal workers.

The ideal worker norm originates from the social roles that men and women have traditionally occupied (work and home, respectively) and that people have come to expect them to occupy (Williams, 2000). According to social role theory (Eagly, 1987), people expect women and men to embody roles they have commonly seen them perform in the culturenamely domestic roles for women and work roles for men. Because men have been traditionally linked with the work role, they are by default considered more ideal workers compared to women who have been traditionally linked with the role of caregiver in the home. Thus, individuals simply assume that men will have the characteristics associated with the ideal worker simply because they have historically been in the paid labor force more so than women. They further assume that women cannot serve as ideal workers because they have historically taken care of home 
and family and, as a result, do not have the characteristics of the ideal worker.

At the core of the ideal worker norm is the idea of the nuclear family, with a husband who works outside the home, a stay-at-home wife who takes care of all household and childrearing responsibilities, and their children. This construction of the family assumes that men are able to be wholly committed to work because they have a wife taking care of all non-work responsibilities. However, the family structure assumed by the ideal worker norm is less and less common. For example, the U.S. Census Bureau (2013) reported that only $20 \%$ of households were composed of married couples with children in 2012, down from $40 \%$ in 1970 . Moreover, the number of dual-earner couples, the number of fathers who are primary caregivers, and the number of children who live in households where both parents work have all grown substantially in the past few decades (Bureau of Labor Statistics, 2014).

Additionally, although men report doing more housework and childcare than in the past (Bianchi, 2011), women continue to be primarily responsible for the home and children. Using data from the American Time Use Survey (ATUS) from 2003-2008, Bianchi (2011) reported that women spend approximately 18 hours per week on housework compared to ten for men, and mothers spend 14 hours per week on primary childcare tasks compared to seven for fathers. Women are also more likely to experience the "second shift" - the double duty of housework following a day of paid work-and are expected by the culture to take on the majority of the household and childcare duties even when working outside the home (Acker, 1990; Hochschild, 1989). As such, women have difficulty performing as ideal workers, especially in workplaces with strong ideal worker norms, and are often forced to choose between being a good mother and a good worker due to inflexible and unaccommodating workplace policies and practices.

Research suggests that the second shift may be particularly problematic for women in STEM. In one study, the desire for a family-flexible career was the strongest predictor of women's diminishing aspirations for STEM careers, higher than demands of the occupation or interest factors (Frome et al., 2006). Additional research shows that fear of the second shift may lead women scientists to have fewer children than they would like, that female scientists have fewer children than desired in comparison to male scientists, and that women are more likely to attribute having fewer children than desired to their science careers compared to men (Ecklund \& Lincoln, 2011). Early career female scientists (graduate students and postdoctoral fellows) with fewer children than desired were especially likely to report planning to leave their science careers. Women also report greater academic stress, family stress, and less support of work-life balance compared to men (O'Laughlin \& 
Bischoff, 2005) and may avoid careers in academia due to perceived barriers related to parenthood (van Anders, 2004).

Research also suggests that perceptions of ideal workers differentially affect faculty men and women engaged in childrearing, whereby mothers are perceived as less flexible and rated lower in performance than their male counterparts, even when they report similar involvement in work and family roles (King, 2008). Further, Correll, Benard, and Paik (2007) reported that, compared to women without children, mothers received competence ratings approximately $10 \%$ lower than nonmothers, were given a recommended starting salary of $\$ 11,000$ less than non-mothers, and were only recommended for hire $47 \%$ of the time, whereas nonmothers were recommended $84 \%$ of the time. Mothers were also allowed far less flexibility in their work, held to harsher performance standards, allowed fewer times of being late to work, and needed a significantly higher score on an exam than nonmothers before being considered hirable. In contrast, parenting seems to work in favor of men. Correll et al. (2007) found that fathers were rated as more committed to their jobs than nonfathers, were allowed to be late to work more, and were offered higher salaries than nonfathers. In a similar vein, Heilman and Okimoto (2008) found that mothers applying for a promotion to a traditionally male position were perceived to be less competent and agentic compared to fathers and employees who were not parents; this bias against mothers negatively influenced screening recommendations for the position.

Together, these findings suggest that the ideal work norm-a socialstructural explanation for gender inequity in STEM-provides a better account for why women do not pursue and remain in STEM careers than the individual-level explanation that women simply spend too much time in the private, domestic sphere to be good workers. This research on stereotypes about model workers, the second shift, and the motherhood bias point to the myriad ways in which societal ideologies about gender and work serve to limit women's participation in male dominated occupations like STEM, challenging the idea that women are simply too concerned about the private sphere of home and family to gain gender parity in STEM.

Practical recommendations for I-O psychologists. As I-O psychologists, we have skills in job design and redesign. In order to increase gender parity in STEM, we should use these skills to reimagine workplaces that do not require workers to meet the ideal worker norm in order to be successful. As an academic and practice science, we have already demonstrated that flextime and telecommuting allow employees to work at different locations and hours and still successfully perform. Notably, these practices do not help only women; men benefit from flextime and telecommuting as well. This area is 
a prime example of how creating workplaces that help achieve gender parity will actually improve work-life balance for all.

Job design analyses can also be used to determine if there are some workplace practices and expectations that (a) are different in their effects on men and women and (b) if so, can be changed without affecting functioning at the individual and organizational level. A simple example comes from academia: scheduling faculty meetings so that they end before after school care pick up. Many departments schedule their meetings for very late or very early in the day (even outside normal working hours) in order to increase the time slots that faculty are available for teaching, but this means that parents who have to pick up children cannot fully participate in these meetings. By rearranging teaching assignments and teaching times, this problem can be reduced and parents can fully participate in departmental life. The same is true for organizations more generally.

\section{Conclusion}

In this article, we examined the different explanations regarding gender inequity in STEM fields produced by the individual lens and the socialstructural lens. We described three myths that legitimize gender inequity in fields like STEM by making gender inequity an issue that originates in the choices, behaviors, and expectations of individual women. In essence, this individual-level explanation for gender inequality suggests that women are responsible for the injustice they experience. We challenged these myths by describing alternative social-structural explanations that result from societal ideologies about gender and work. In so doing, we argue that gender inequity in the workplace, including in the STEM workforce, is not a problem for individual women but a social-structural problem that deserves attention from all members of society-men and women. It is also one in which I-O psychologists are uniquely suited to tackle by promoting a shift in how we think about gender and work and by reimagining how, when, and where work is accomplished-and by whom it is accomplished. We are issuing a call to I-O psychologists to begin addressing gender inequity in STEM as a problem we all share rather than one that should be left to individual women. Together, by making it "our" problem, we can help combat gender inequity in STEM fields, the workplace, and society.

\section{References}

Acker, J. (1990). Hierarchies, jobs, bodies: A theory of gendered organizations. Gender \& Society, 4, $139-158$.

Bagilhole, B., \& Goode, J. (2001). The contradiction of the myth of individual merit, and the reality of a patriarchal support system in academic careers: A feminist investigation. European Journal of Women's Studies, 8(2), 161-180. 
Bakan, D. (1966). The duality of human existence: An essay on psychology and religion. Chicago, IL: Rand McNally.

Bench, S. W., Lench, H. C., Liew, J., Miner, K., \& Flores, S. A. (2015). Gender gaps in overestimation of math performance. Sex Roles, 72(11-12), 536-546.

Berger Peter, L., \& Luckmann, T. (1966). The social construction of reality: A treatise in the sociology of knowledge. Garden City, NY: First Anchor.

Bergman, M. E., Walker, J. M., \& Jean, V. A. (2016). A simple solution to policing problems: Women! Industrial and Organizational Psychology, 9(3), 590-597.

Bertrand, M., \& Mullainathan, S. (2004). Are Emily and Greg more employable than Lakisha and Jamal? A field experiment on labor market discrimination. The American Economic Review, 94(4), 991-1013.

Bianchi, S. M. (2011). Changing families, changing workplaces. The Future of Children, 21, 15-26.

Biernat, M., Vescio, T. K., \& Theno, S. A. (1996). Violating American values: A "value congruence" approach to understanding outgroup attitudes. Journal of Experimental Social Psychology, 32(4), $387-410$.

Bureau of Labor Statistics. (2014). Employment characteristics of families-2013. Retrieved from http: //www.bls.gov/news.release/pdf/famee.pdf.

Bureau of Labor Statistics. (2016). Labor force statistics from the Current Population Survey. Washington, DC: Bureau of Labor Statistics, Department of Labor. Retrieved from http://dx.doi.org/ www.bls.gov/cps/cpsaat11.htm.

Cech, E. A., \& Blair-Loy, M. (2010). Perceiving glass ceilings? Meritocratic versus structural explanations of gender inequality among women in science and technology. Social Problems, 57(3), 371-397.

Ceci, S. J., Williams, W. M., \& Barnett, S. M. (2009). Women's underrepresentation in science: Sociocultural and biological considerations. Psychological Bulletin, 135(2), 218-261.

Cheryan, S., Plaut, V. C., Davies, P. G., \& Steele, C. M. (2009). Ambient belonging: How stereotypical cues impact gender participation in computer science. Journal of Personality and Social Psychology, 97(6), 1045-1060.

Christopher, A. N., \& Mull, M. S. (2006). Conservative ideology and ambivalent sexism. Psychology of Women Quarterly, 30(2), 223-230.

Correll, S. J. (2001). Gender and the career choice process: The role of biased self-assessments. American Journal of Sociology, 106(6), 1691-1730.

Correll, S. J., Benard, S., \& Paik, I. (2007). Getting a job: Is there a motherhood penalty? American Journal of Sociology, 112, 1297-1338.

Crocker, J., \& Wolfe, C. T. (2001). Contingencies of self-worth. Psychological Review, 108(3), 593-623.

Cropanzano, R., \& Mitchell, M. S. (2005). Social exchange theory: An interdisciplinary review. Journal of Management, 31(6), 874-900.

Department of Labor. (2014). Women in the labor force. Retrieved from http://www.dol.gov/wb/stats/ stats_data.htm\#occs.

Diekman, A. B., Brown, E. R., Johnston, A. M., \& Clark, E. K. (2010). Seeking congruity between goals and roles: A new look at why women opt out of science, technology, engineering, and mathematics careers. Psychological Science, 21(8), 1051-1057.

Eagly, A. H. (1987). Sex differences in social behavior: A social role interpretation. Hillsdale, NJ: Lawrence Erlbaum.

Eagly, A. H., \& Karau, S. J. (2002). Role congruity theory of prejudice toward female leaders. Psychological Review, 109(3), 573-598.

Ecklund, E. H., \& Lincoln, A. E. (2011). Scientists want more children. PLoS ONE, 6(8), e22590.

Emerson, R. M. (1976). Social exchange theory. Annual Review of Sociology, 2(1), 335-362.

Freeman, R. B., \& Huang, W. (2014). Strength in diversity: Richard B. Freeman and Wei Huang reflect on a link between a team's ethnic mix and highly cited papers. Nature, 513(7518), 305-306.

Frome, P. M., Alfeld, C. J., Eccles, J. S., \& Barber, B. L. (2006). Why don't they want a male-dominated job? An investigation of young women who changed their occupational aspirations. Educational Research and Evaluation, 12(4), 359-372. 
Furnham, A. (1982). The Protestant work ethic and attitudes towards unemployment. Journal of Occupational Psychology, 55(4), 277-285.

Gigerenzer, G., \& Selten, R. (2002). Bounded rationality: The adaptive toolbox. Cambridge, MA: MIT Press.

Gilbert, D.T., \& Malone, P.S. (1995). The corresponding bias. Psychological Bulletin, 117(1), 21-38.

Goldin, C., \& Rouse, C. (2000). Orchestrating impartiality: The impact of" blind" auditions on female musicians. American Economic Review, 90(4), 715-742.

Gorman, E. H. (2005). Gender stereotypes, same-gender preferences, and organizational variation in the hiring of women: Evidence from law firms. American Sociological Review, 70(4), 702-728.

Harton, H. C., \& Lyons, P. C. (2003). Gender, empathy, and the choice of the psychology major. Teaching of Psychology, 30(1), 19-24.

Heaven, P. C. (1990). Human values and suggestions for reducing unemployment. British Journal of Social Psychology, 29(3), 257-264.

Heilman, M. E. (1983). Sex bias in work settings: The lack of fit model. Research in Organizational Behavior, 5, 269-298.

Heilman, M. E. (2001). Description and prescription: How gender stereotypes prevent women's ascent up the organizational ladder. Journal of Social Issues, 57(4), 657-674.

Heilman, M. E., \& Okimoto, T. G. (2008). Motherhood: a potential source of bias in employment decisions. Journal of Applied Psychology, 93(1), 189-198.

Henrich, J., Heine, S.J., \& Norenzayan, A. (2010). The weirdest people in the world? Behavioral and Brain Science, 33, 61-83.

Hilton, J. L., \& Von Hippel, W. (1996). Stereotypes. Annual Review of Psychology, 47(1), 237-271.

Hochschild, A. (1989). The second shift. New York, NY: Avon Books.

Hofstede, G. H. (2001). Culture's consequences: Comparing values, behaviors, institutions, and organizations across nations (2nd edition). Thousand Oaks, CA: Sage.

House, R. J., Hanges, P. J., Javidan, M., Dorfman, P. W., \& Gupta, V. (Eds.) (2004). Culture, leadership, and organizations: The GLOBE Study of 62 societies. Thousand Oaks, CA: Sage.

IU Bloomington Newsroom. (2015, March 26). Stereotypes lower math performance in women, but effects go unrecognized, IU study finds. IU Bloomington Newsroom. Retrieved from http://news. indiana.edu/releases/iu/2015/03/stereotype-threats.shtml.

Jost, J. T., Banaji, M. R., \& Nosek, B. A. (2004). A decade of system justification theory: Accumulated evidence of conscious and unconscious bolstering of the status quo. Political Psychology, 25(6), 881-919.

Ju, A. (2011, February 7). Choices-not discrimination-determine women scientists' success, researchers say. Cornell Chronicle. Retrieved from http://www.news.cornell.edu/stories/2011/02/ choices-not-discrimination-deter-women-scientists.

Juhn, C., \& Potter, S. (2006). Changes in labor force participation in the United States. The Journal of Economic Perspectives, 20(3), 27-46.

Kahneman, D. (2003). A perspective on judgment and choice-mapping bounded rationality. American Psychologist, 58, 697-720.

Kahneman, D. (2011). Thinking, fast and slow. Basingstoke, UK: Macmillan.

King, E. B. (2008). The effect of bias on the advancement of working mothers: Disentangling legitimate concerns from inaccurate stereotypes as predictors of advancement in academe. Human Relations, 61, 1677-1711.

Kluegel, J. R., \& Smith, E. R. (1986). Beliefs about inequality: Americans' views of what is and what ought to be. New York, NY: Aldine de Gruyter.

Krefting, L. A. (2003). Intertwined discourses of merit and gender: Evidence from academic employment in the USA. Gender, Work \& Organization, 10(2), 260-278.

Kricheli-Katz, T. (2012). Choice, discrimination, and the motherhood penalty. Law \& Society Review, 46(3), 557-587.

Kricheli-Katz, T. (2013). Choice-based discrimination: Labor-force-type discrimination against gay men, the obese, and mothers. Journal of Empirical Legal Studies, 10(4), 670-695. 
Leary, M. R., \& Baumeister, R. F. (2000). The nature and function of self-esteem: Sociometer theory. Advances in Experimental Social Psychology, 32, 1-62.

Lerner, M. J. (1980). The belief in a just world: A fundamental delusion. New York: Springer US.

Lonsway, K., Wood, M., Fickling, M., De Leon, A., Moore, M., Harrington, P., ...Spillar, K. (2002). Men, women, and police excessive force: A tale of two genders. A content analysis of civil liability cases, sustained allegations, \& citizen complaints. Arlington, VA: The National Center for Women \& Policing. Retrieved from http://www.womenandpolicing.org/PDF/2002_Excessive_ Force.pdf.

Lorber, J. (1994). Paradoxes of gender. New Haven, CT: Yale University Press.

Lyness, K. S., \& Heilman, M. E. (2006). When fit is fundamental: Performance evaluations and promotions of upper-level female and male managers. Journal of Applied Psychology, 91(4), 777-785.

March, J. G., \& Simon, H. A. (1958). Organizations. New York, NY: Wiley.

Margolis, J., \& Fisher, A. (2002). Unlocking the clubhouse: Women in computing. Cambridge, MA: MIT Press.

Markus, H. R., \& Kitayama, S. (1991). Culture and the self: Implications for cognition, emotion, and motivation. Psychological Review, 98(2), 224-253.

Markus, H. R., \& Kitayama, S. (2003, January). Models of agency: Sociocultural diversity in the construction of action. In V. Murphy-Berman \& J. J. Berman (Eds.), Nebraska symposium on motivation: Cultural differences in perspectives on the self (pp. 1-58). Lincoln, NE: University of Nebraska Press.

Martin, P. Y. (2001). "Mobilizing masculinities": Women's experiences of men at work. Organization, $8(4), 587-618$.

Martin, P. Y. (2003). "Said and done" versus "saying and doing" gendering practices, practicing gender at work. Gender \& Society, 17(3), 342-366.

Martin, P. Y. (2006). Practising gender at work: Further thoughts on reflexivity. Gender, Work \& Organization, 13(3), 254-276.

McAdams, D. P., \& Pals, J. L. (2006). A new big five: Fundamental principles for an integrative science of personality. American Psychologist, 61(3), 204-217.

McArdle, E. (2008, 18 May). The freedom to say "no." The Boston Globe. Retrieved from http://www. boston.com/bostonglobe/ideas/articles/2008/05/18/the_freedom_to_say_no/.

Miller, G. E. (2004). Frontier masculinity in the oil industry: The experience of women engineers. Gender, Work \& Organization, 11(1), 47-73.

Morrow, P. C. (1993). The theory and measurement of work commitment. Greenwich, CT: JAI Press Inc.

Mosisa, A., \& Hipple, S. (2006). Trends in labor force participation in the United States. Monthly Labor Review, 129, 35-57.

Moss-Racusin, C. A., Dovidio, J. F., Brescoll, V. L., Graham, M. J., \& Handelsman, J. (2012). Science faculty's subtle gender biases favor male students. Proceedings of the National Academy of Sciences, 109(41), 16474-16479.

National Science Foundation. (2015). Report on women, minorities, and persons with disabilities in science and engineering. Retrieved from https://www.nsf.gov/statistics/2015/nsf15311/start. $\mathrm{cfm}$.

Nickerson, R. S. (1998). Confirmation bias: A ubiquitous phenomenon in many guises. Review of General Psychology, 2(2), 175-220.

Nosek, B. A., Smyth, F. L., Sriram, N., Lindner, N. M., Devos, T., Ayala, A., ... \& Kesebir, S. (2009). National differences in gender-science stereotypes predict national sex differences in science and math achievement. Proceedings of the National Academy of Sciences, 106(26), 10593-10597.

O’Laughlin, E. M., \& Bischoff, L. G. (2005). Balancing parenthood and academia: Work/family stress as influenced by gender and tenure status. Journal of Family Issues, 26, 79-106.

O'Reilly, J., \& Robinson, S. L. (2009). The negative impact of ostracism on thwarted belongingness and workplace contributions. Academy of Management Proceedings, 1, 1-7. 
Patall, E. A., Cooper, H., \& Robinson, J. C. (2008). The effects of choice on intrinsic motivation and related outcomes: A meta-analysis of research findings. Psychological Bulletin, 134(2), 270-300.

Pazy, A., \& Oron, I. (2001). Sex proportion and performance evaluation among high-ranking military officers. Journal of Organizational Behavior, 22(6), 689-702.

Phillips, K. W. (2015, June 11). Gender and racial bias is systemic in the sciences. New York Times. Retrieved from http://www.nytimes.com/roomfordebate/2015/06/11/ nobel-winning-sexism-in-the-lab/gender-and-racial-bias-is-systemic-in-the-sciences.

President's Council of Advisors on Science and Technology. (2012). Speech by Dr. Willie E. May. Retrieved from https://www.nist.gov/speech-testimony/ presidents-council-advisors-science-and-technology.

Ratcliffe, R. (2015, June 10). Noble scientist Tim Hung: Female scientists cause trouble for men in labs. The Guardian. Retrieved from https:/www.theguardian.com/uk-news/2015/jun/10/ nobel-scientist-tim-hunt-female-scientists-cause-trouble-for-men-in-labs.

Ren, L. R., Paetzold, R. L., \& Colella, A. (2008). A meta-analysis of experimental studies on the effects of disability on human resource judgments. Human Resource Management Review, 18(3), 191203.

Ridgeway, C. (1991). The social construction of status value: Gender and other nominal characteristics. Social Forces, 70(2), 367-386.

Ridgeway, C. L. (1997). Interaction and the conservation of gender inequality: Considering employment. American Sociological Review, 62(2), 218-235.

Ridgeway, C. L., \& Correll, S. J. (2004). Unpacking the gender system a theoretical perspective on gender beliefs and social relations. Gender \& Society, 18(4), 510-531.

Rosenbloom, J.L., Ash, R.A., Dupont, B., \& Coder, L. (2008). Why are there so few women in information technology? Assessing the role of personality in career choices. Journal of Economic Psychology, 29, 543-554.

Rousseau, D. M., \& McLean Parks, J. (1993). The contracts of individuals and organizations. Research in Organizational Behavior, 15, 1-43.

Savani, K., \& Rattan, A. (2012). A choice mind-set increases the acceptance and maintenance of wealth inequality. Psychological Science, 23(7), 796-804.

Savani, K., Stephens, N. M., \& Markus, H. R. (2011). The unanticipated interpersonal and societal consequences of choice victim blaming and reduced support for the public good. Psychological Science, 22(6), 795-802.

Schmader, T., Johns, M., \& Barquissau, M. (2004). The costs of accepting gender differences: The role of stereotype endorsement in women's experience in the math domain. Sex Roles, 50(11-12), 835-850.

Schott, G., \& Selwyn, N. (2000). Examining the "male, antisocial" stereotype of high computer users. Journal of Educational Computing Research, 23(3), 291-303.

Schuck, A. M., \& Rabe-Hemp, C. (2007). Women police: The use of force by and against female officers. Women \& Criminal Justice, 16, 91-117.

Sedikides, C., \& Strube, M. J. (1997). Self-evaluation: To thine own self be good, to thine own self be sure, to thine own self be true, and to thine own self be better. Advances in Experimental Social Psychology, 29, 209-269.

Settles, I. H., \& O’Connor, R. C. (2014). Incivility at academic conferences: Gender differences and the mediating role of climate. Sex Roles, 71(1-2), 71-82.

Sidanius, J., \& Pratto, F. (1999). Social dominance: An intergroup theory of social hierarchy and oppression. Cambridge, MA: Cambridge University Press.

Silvia, P. J., \& Duval, T. S. (2001). Objective self-awareness theory: Recent progress and enduring problems. Personality and Social Psychology Review, 5(3), 230-241.

Simon, H. A. (1991). Cognitive architectures and rational analysis: Comment. In K. VanLehn (Ed.), Architectures for intelligence (pp. 25-39). Hillsdale, NJ: Erlbaum.

Smith-Lovin, L., \& McPherson, J. M. (1993). You are who you know: A network approach to gender. In P. England (Ed.), Theory on gender: Feminism on theory, 223-251. Hawthorne, NY: Aldine de Gruyter. 
Spillar, K. (2015, July 2). How more female police officers would help stop police brutality. The Washington Post. Retrieved from https://www.washingtonpost.com/posteverything/wp/ 2015/07/02/how-more-female-police-officers-would-help-stop-police-brutality/?utm_term= $.517 \mathrm{a} 604 \mathrm{c} 8 \mathrm{e} 62$.

Spillar, K., Harrington, P., Wood, M., Aguirre, P., Aguilar, S., Yick, J., ... Meza, L. (2000). Gender differences in the cost of police brutality and misconduct: A content analysis of LAPD civil liability cases: 1990-1999. Arlington, VA: The Feminist Majority Foundation and The National Center for Women \& Policing. Retrieved from http://www.womenandpolicing.org/ExcessiveForce.asp? $\mathrm{id}=4516$.

Steinpreis, R. E., Anders, K. A., \& Ritzke, D. (1999). The impact of gender on the review of the curricula vitae of job applicants and tenure candidates: A national empirical study. Sex Roles, 41(7-8), 509-528.

Stephens, N. M., \& Levine, C. S. (2011). Opting out or denying discrimination? How the framework of free choice in American society influences perceptions of gender inequality. Psychological Science, 22(10), 1231-1236.

Summers, L. H. (2005). Remarks at NBER conference on diversifying the science \& engineering workforce. Retrieved April 19, 2018 from https://www.harvard.edu/president/speeches/summers 2005/nber.php.

Swim, J. K., Aikin, K. J., Hall, W. S., \& Hunter, B. A. (1995). Sexism and racism: Old-fashioned and modern prejudices. Journal of Personality and Social Psychology, 68(2), 199-214.

Triandis, H.C. (1995) Individualism \& collectivism: New directions in social psychology. Boulder, CO: Westview Press.

Trix, F., \& Penska, C. (2003). Exploring the color of glass: Letters of recommendation for female and male medical faculty. Discourse \& Society, 14, 191-220.

Tversky, A., \& Kahneman, D. (1974). Judgment under uncertainty: Heuristics and biases. Science, 185, $1124-1131$.

U.S. Census Bureau. (2013). America's family and living arrangements: 2012. Retrieved April 23, 2018 from https://www.census.gov/prod/2013pubs/p20-570.pdf.

Valian, V. (1999). Why so slow? The advancement of women. Cambridge, MA: MIT Press.

van Anders, S. M. (2004). Why the academic pipeline leaks: Fewer men than women perceive barriers to becoming professors. Sex Roles, 51, 511-521.

Van Hoorn, A., \& Maseland, R. (2013). Does a Protestant work ethic exist? Evidence from the wellbeing effect of unemployment. Journal of Economic Behavior \& Organization, 91, 1-12.

Weber, M. (1958). The Protestant ethic and the spirit of capitalism: The relationship between religion and the economic and social life of modern culture. New York, NY: Charles Scribner's Sons.

Wennerås, C., \& Wold, A. (1997). Nepotism and sexism in peer-review. Nature, 387(6631), 341-343.

Williams, J. (2000). Unbending gender: Why family and work conflict and what to do about it. Oxford, UK: Oxford University Press. 